\title{
A Systematic Review of Creative Self-Efficacy Literature in Education
}

\author{
Aycin Unal ${ }^{1,2^{*}}$, Mehmet Fatih Tasar ${ }^{1}$ \\ ${ }^{1}$ Gazi University, TURKEY \\ ${ }^{2}$ Mugla Science and Art Center, TURKEY
}

Received 2 October 2021 - Accepted 17 November 2021

\begin{abstract}
In this article we reviewed literature related to creative self-efficacy in the field of education. We narrowed down the review to eighty-eight articles. We formed categories according to (1) publication year, (2) country of study, (3) sample/study group, (4) method used, and (5) subject matter addressed. The first study was published in 2004. The frequency of publications increased in the last three years. USA, China, and Taiwan are the leading countries in terms of origin of published articles. Except four inter-cultural studies, all others were conducted in a single country. About half of the studies were conducted with $\mathrm{K}-12$ students and teachers, and the remaining focused on higher education students and instructors. Mostly quantitative methods have been utilized. Lastly, we categorized the issues tackled into nine themes. Researchers gave a heavy emphasis on investigating creativity/creativity indicators, individual/environmental factors and less emphasis on academic performance in relation to creative self-efficacy.
\end{abstract}

Keywords: creative self-efficacy, educational research, systematic review

\section{INTRODUCTION}

Discussions about creativity started in 1950 with the publication of J. P. Guilford's thoughts on psychometrics and personality traits and were shaped by educators such as Paul Torrance (Cropley, 2011). Although Guilford focused on the relationship between learning and creativity, other aspects of creativity have also been focused on in recent years. In recent years, researchers conducted numerous research to reveal the mechanisms of creativity and the factors that foster creativity (etc. Boden, 2009; Choi, 2004; Hong et al., 2009; Karwowski \& Barbot, 2016; Tierney \& Farmer, 2002, 2011). At this point, we came across the concept of self-efficacy in relation to creativity. Bandura defined self-efficacy as "beliefs in one's capabilities to organize and execute the courses of action required to produce given attainments" (1997, p. 3). The concept of self-efficacy has been applied in many different areas such as career development, leadership, rewards and incentives, performance appraisal, job design (Locke, 1997). Mathisen and Bronnick (2009) asserted that "Creative self-efficacy is derived from Bandura's (1997) more general concept of self-efficacy, explained as a person's belief that he or she can successfully perform in a particular setting. Bandura recognized a likely relationship between self-efficacy and creative performance." Tierney and Farmer (2002) defined that "creative self-efficacy as the belief that one has the ability to produce creative outcomes". Similarly, Beghetto (2009) and Abbott (2010, p. 12) defined creative self-efficacy (CSE) as one's own judgment of one's competence in generating new and appropriate ideas, finding creative solutions, and exhibiting creative behaviors. According to Hung and Lin (2005), CSE for students is in the belief that a person has the ability to perform tasks creatively in the school setting (as cited in Hung, 2018). Beghetto (2013, p. 11) stated that CSE, like other forms of self-efficacy, is affected by people's previous experiences in expressing their creative ideas and the supportive feedback they receive.

Our review of the literature showed that CSE studies have attracted great attention in the creative studies literature in recent years. Numerous studies related to CSE exist in the fields of business (etc. Jaiswal \& Dhar, 2015; Shin et al., 2012; Tierney \& Farmer, 2011) and education (etc. Beghetto, 2006; Liu et al., 2014; Qiang et al., 2020). Companies, research centers, educational institutions spend efforts to understand how to increase creativity and innovation (Puente-Díaz, 2016). At this point, CSE has important implications for

(c) 2021 by the authors; licensee Modestum. This article is an open access article distributed under the terms and conditions of the Creative Commons Attribution License (http://creativecommons.org/licenses/by/4.0/). 


\section{Contribution to the literature}

- To the best of our knowledge, this is the first systematic literature review on the topic of creative selfefficacy in relation to education.

- Thus, we reviewed the literature in order to lay out the current outlook and to reveal the gaps.

- This review of the literature will serve as a reference point for current and future researchers, policy makers, and practitioners.

understanding creativity and innovation (Puente-Díaz, 2016). Even though educational approaches that include creativity and innovation for meaningful learning, such as STEM, have a good impact on students' creativity (Hanif et al., 2019), in our literature search, only two CSE publications related to STEM education were found. The first study (Hong et al., 2019) investigated how learners acquire CSE related to two types of epistemic curiosity and how they reflect their knowledge and creativity to understand STEM learning. The second study (Broekhoven et al., 2020) explored the differences in creativity, as well as the extent and nature of these differences in the fields of art and science, STEM, and engineering.

In addition, there exists several meta-analysis studies on CSE in the literature. In their meta-analysis Karwowski and Lebuda (2016) investigated the relationships between creative self-beliefs (i.e., CSE, creative personal identity, and self-rated creativity) and personality traits. Puente-Diaz (2016) reviewed the empirical literature examining the antecedents and consequences of CSE in the field of study, using individual creative action theory and social cognitive theory to locate CSE in the creativity and innovation process and explore how CSE is measured. Further, Tang et al. (2017) reviewed their CSE studies from the Chinese perspective. Haase et al. (2018), on the other hand, investigated the relationships between CSE and measures of creativity in their meta-analysis study.

Despite all these publications, there is no literature review examining the studies on CSE, especially in the field of education. Literature reviews are important to place for determining gaps and new study areas by synthesizing existing studies on the subject. With a literature review, researchers can see conducted studies collectively on a certain topic, they can contain information about similar research results, and give researchers an idea about areas lacking research (Fraenkel et al., 2012, p. 38).

In this study, we conducted a systematic literature review of the studies on CSE in the field of education. This study is important in terms of showing the gaps and current trends in research in the field of education on CSE and guiding future studies.

The aim of this review is to show the gaps by examining the studies in the field of education on CSE and to become a guide for future research. Therefore, in this study, we seek answers to the following questions:
What pattern does the distribution of CSE studies have across

1. years?

2. countries?

3. methods?

4. sample/study groups?

5. issues/themes?

\section{METHODS}

In this study, we conducted the systematic literature review method. By using the systematic literature review method, we can make sense of large masses of information, reveal gaps in the literature and what we need to know (Petticrew \& Roberts, 2006, p. 2). According to Oxman (1994), for a systematic literature review, first of all, the focus of the study is determined, and relevant studies are reached. Inclusion and exclusion criteria are appraised, eligible studies are identified, and the identified articles are critically evaluated, synthesized, and concluded (Oxman, 1994). This method can provide guidance to researchers and research users with appropriate summaries (Petticrew \& Roberts, 2006, p. xiii).

\section{Search in Databases}

Our initial search on Web of Science ${ }^{\circledR}$ and The Education Resources Information Center (ERIC) with the keyword "creative self-efficacy" yielded 352 items in the Web of Science ${ }^{\circledR}$ and 72 items in ERIC. When we excluded the duplicate articles from the 424 articles reached, we reached 377 articles.

We identified five key criteria before including the articles in our systematic literature review. While determining these criteria, a previous systematic literature review study by Schott et al. (2020) and the inclusion and exclusion criteria published by Condron (2016) were used.

1. Centrality of topic: We included only those articles focusing centrally on CSE.

2. Participants: We included articles of whose participants that were students and teachers at both the K-12 and higher education (undergraduate, master and PhD). We excluded articles conducted in the field of the business (even if they include educational work such as inservice training, workshop, seminar, etc.). 


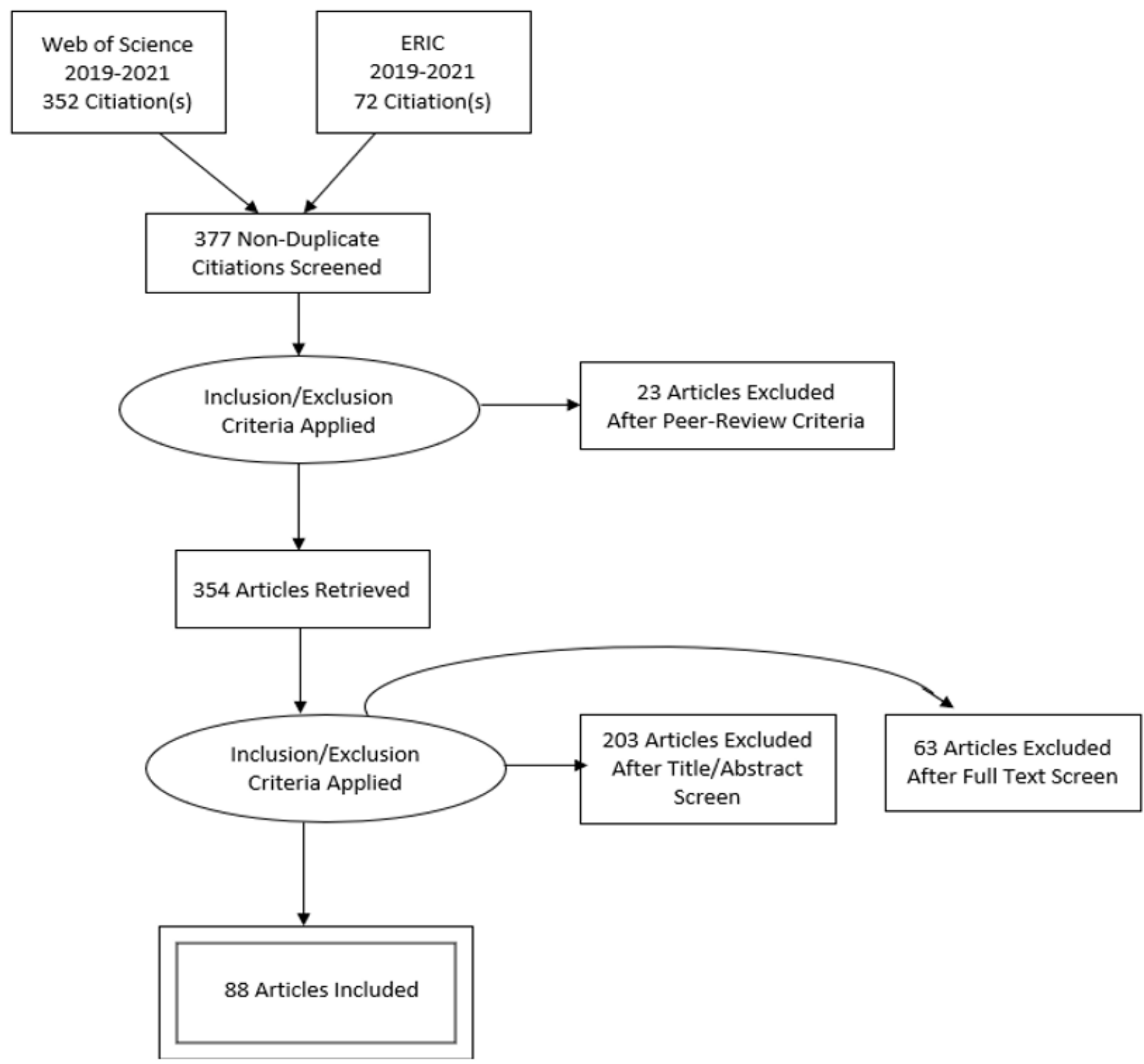

Figure 1. PRISMA flowchart

3. Study design: All studies that had qualitative, quantitative, and mixed methods were included in the study. In order not to include the studies twice, the symposium entries on the subject were excluded from the scope of the study.

4. Language: Only articles written in English were included in the study.

5. Publication status: To ensure that we have access to high-quality educational research on CSE, we made sure that the publication status of selected articles was "peer-reviewed".

We reviewed 377 identified articles according to our inclusion/exclusion criteria and excluded non-peerreviewed articles. Thus, the number of reviewed articles decreased to 354 . The titles and abstracts of the studies were evaluated. As a result of this evaluation, studies with K12, higher education students, and teachers were included, studies in other fields (business, health, etc.) or not directly related to education were excluded. Thereby, 151 articles matching our review criteria were identified. The full texts of these articles were carefully reviewed, and 63 more articles that were not directly related to the topic of CSE or that did not include educational studies at K12/ higher education levels were excluded. As a result, a total of 88 articles were reviewed within the scope of the study. The selection process is shown in Figure 1.

\section{RESULTS}

\section{Years}

The first study that met the criteria and was published in 2004. Our search yielded no entries for years 2005, 2008, and 2013. The number of studies was highest in 2020 (23\%, n=20), 2019 (14\%, n=12), and 2021 $(14 \%, n=12)$. When evaluating the results, it's necessary to take into account that the articles last published in July 2021 are also included in the scope of the review.

Moreover, the articles included in this research were published in 38 different journals. The journals in which most articles were published $(n>10)$ were the Thinking 


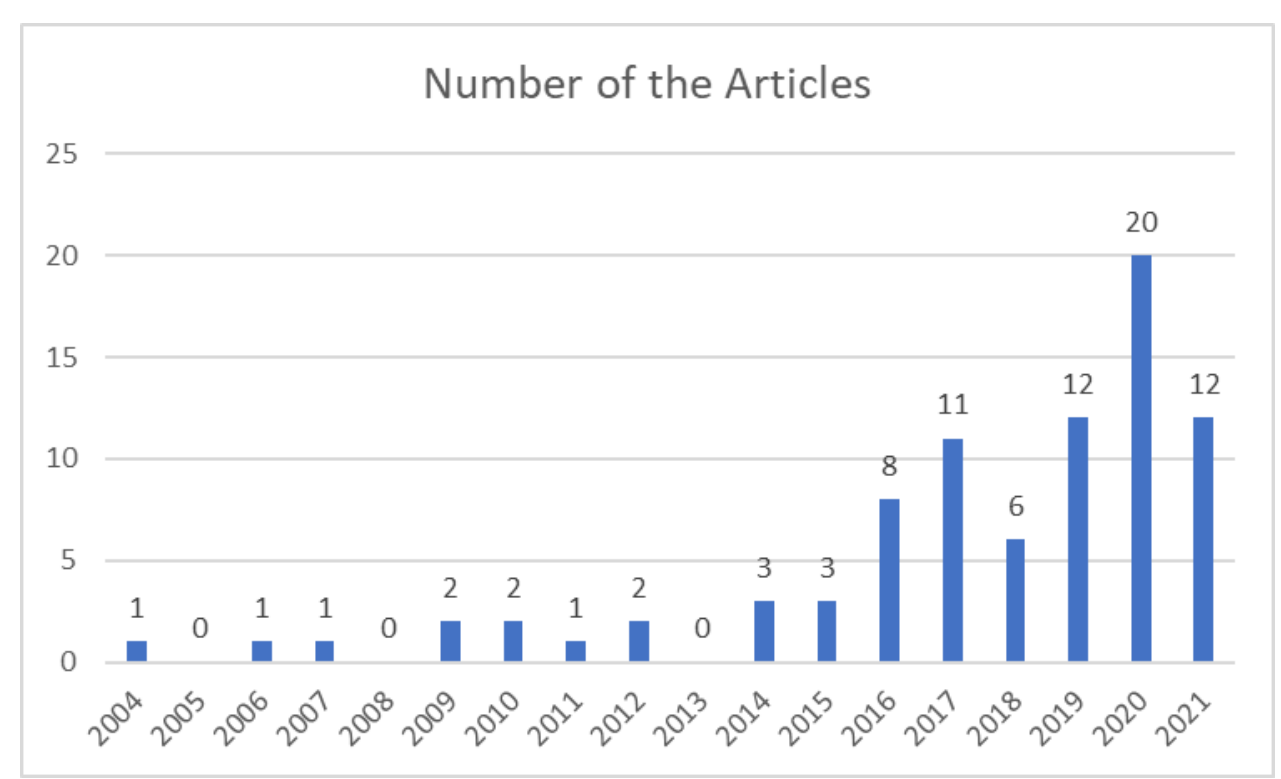

Figure 2. Distribution of articles across years

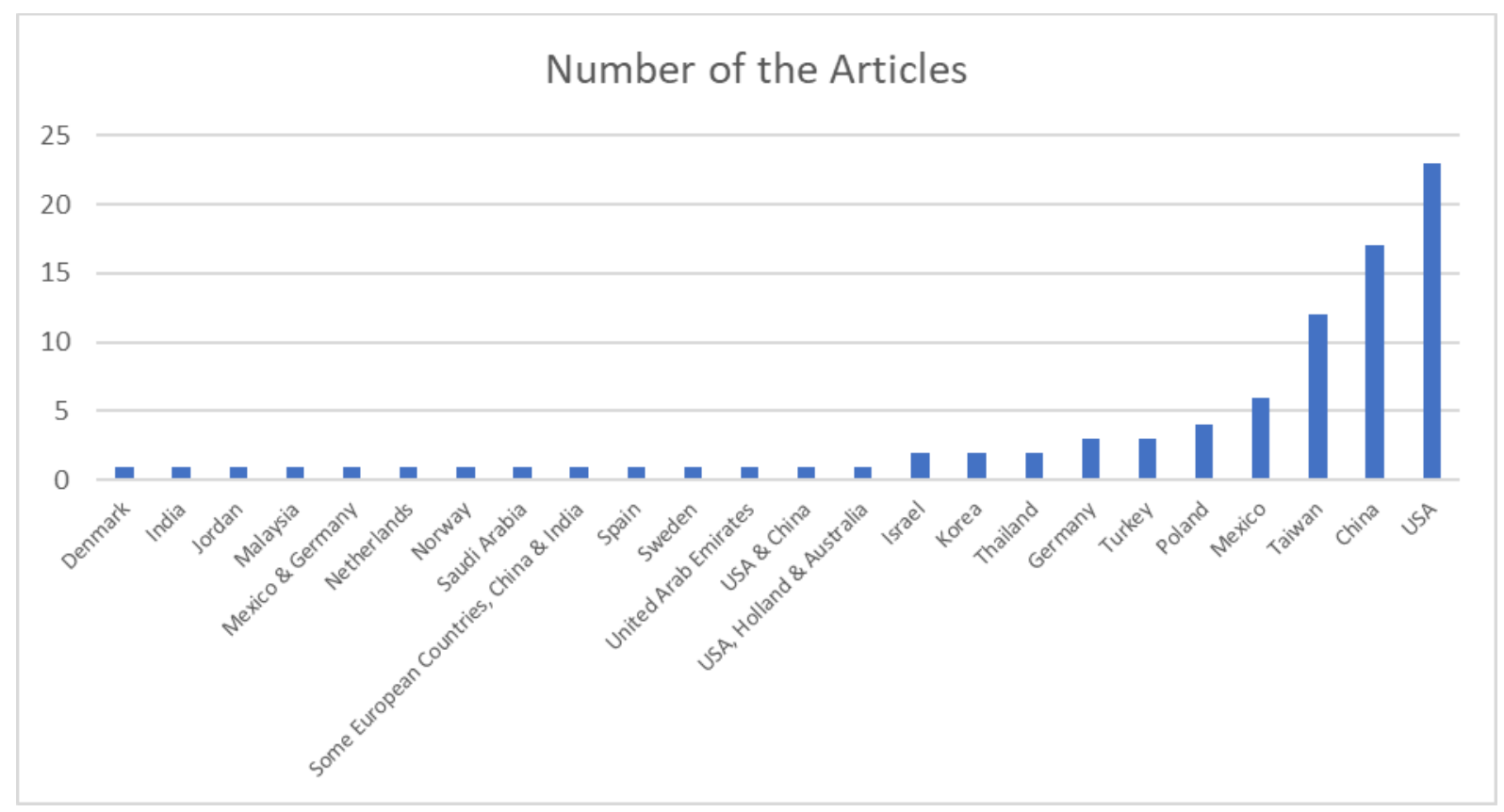

Figure 3. Distribution of articles by country

Skills in Creativity, The Journal of Creative Behavior, and the Creativity Research Journal. These are peerreviewed academic journals that provide research into different aspects of creativity. Furthermore, our review also includes journals directly focusing on education (n $>3$ ), such as the Journal of Research in Science Teaching, and the International Journal of Educational Research.

\section{Countries}

Once the studies on CSE in the field of education were examined, we found out that the studies were carried out in 20 different countries. The majority of the studies reviewed were conducted in the United States. $(27 \%, \mathrm{n}=24)$. In addition, it is noteworthy that many studies were carried out in Asian countries such as China $(19 \%, n=17)$, and Taiwan $(13 \%, n=12)$. Only four studies employed an intercultural approach (Aylesworth \& Cleary, 2020; Katz-Buonincontro et al., 2021; Puente-Diaz et al., 2020; Tang \& Werner, 2017). The distribution of the articles by country is given in Figure 3.

\section{Methods}

It was determined that only one of the 88 studies was a theoretical meta-analysis study. Only quantitative methods were used in 81 of the studies (92\%). Three of the studies that included quantitative methods included scale adaptation studies (Alotaibi, 2016; Hung, 2018; 
Table 1. Types of Subjects/Participants in CSE in Education Studies

\begin{tabular}{lll}
\hline Subjects/Participants & Number/percentage of studies Sample study \\
\hline Primary school students & $10 / 11.5 \%$ & Kong et al. (2018) \\
Elementary school studentst their teachers & $2 / 2.3 \%$ & Hartley et al. (2016) \\
Elementary and junior high school students & $1 / 1.2 \%$ & Liang and Yuan (2020) \\
Middle school students & $7 / 8 \%$ & Sun et al. (2021) \\
Middle school students and their teachers & $1 / 1.2 \%$ & Karwowski et al. (2015) \\
Middle and secondary students & $2 / 2.3 \%$ & Beghetto (2006) \\
High school students & $7 / 8 \%$ & Chang et al. (2019) \\
K12 teachers & $8 / 9.1 \%$ & Li et al. (2017) \\
Undergraduate students & $39 / 45 \%$ & Tep et al. (2021) \\
Undergraduate and graduate students & $3 / 3.4 \%$ & Park et al. (2021) \\
Bachelor's, master's, and doctoral students & $1 / 1.2 \%$ & Katz-Buonincontro et al. (2020a) \\
Undergraduate students and their teachers & $2 / 2.3 \%$ & Ovbiagbonhia et al. (2020) \\
Graduate students & $2 / 2.3 \%$ & Gu et al. (2017) \\
University teachers & $1 / 1.2 \%$ & Lingke and Chang (2019) \\
University, high school, and junior high school students & $1 / 1.2 \%$ & Hung (2018) \\
Total & $87 / 100 \%$ &
\end{tabular}

Atabek, 2020). In articles using quantitative methods, questionnaires (paper and pen survey, questionnaire, survey) were mostly used (e.g., Beghetto, 2006; Yang et al., 2020; Woodcock et al., 2019). Only 5 (5.7\%) of the reviewed articles used mixed-method and only one article used the qualitative methods. Surveys and interviews were generally used in mixed-method studies (e.g., Alt \& Raichel, 2020; Byrge \& Tang, 2015). In addition, the observer ratings, anecdotal records, written plans were also used (e.g., Atwood-Blaine et al., 2019; Katz-Buonincontro et al., 2020b). An open-ended survey was used in the research that applied the qualitative method (Lemons, 2010).

\section{Settings and Participants}

In the theoretical meta-analysis study, 41 articles were examined. When the remaining studies are examined, $44 \% \quad(n=39)$ of the studies were carried out with K12 students and teachers, while $56 \%(n=49)$ were carried out with undergraduate and graduate students and their teachers. It is seen that the participants of the study were middle school, high school, and university students. The information about sample/study groups that took part in the reviewed studies is provided in Table 1.

\section{Research Issues/Themes}

We conducted a content analysis by examining the studies in the field of education on CSE. Two researchers leading the systematic review noted the potential codes that emerged from the studies. At the first stage, we looked at the correlation between the results obtained to ensure intercoder reliability. For this purpose, we used the reliability formula of Miles and Huberman (1994). According to Miles and Huberman (1994), if the reliability calculations are over $70 \%$, it is considered reliable for the research. As a result of the first calculation, we found the reliability of the study to be
$86 \%$. At subsequent meetings, we discussed the importance of these codes and compared/checked the significance of the difference between the proposed codes. Then, we formed the categories by identifying the common aspects between the codes. As a result of the meetings, complete harmony was achieved between the researchers. By obtaining expert opinion we formed nine final themes (see Figure 4).

Since some studies fell into more than one category, the total number given in Table 2 and the total number of studies do not match. Hence, we included only frequencies in Table 2.

Table 2 shows that studies on the relationship of CSE with creativity/creativity indicators $(n=18)$ and individual/environmental factors $(n=16)$ have the highest frequency among all others (total=88). The former group examined the relationships between CSE and creativity (Broekhoven at al., 2020; Haase et al., 2018); CSE and creative performance (Chang \& Jaisook, 2020; Lemons, 2010; Li \& Wu, 2011; Paek et al., 2016; Park et al., 2021; Reiter-Palmon et al., 2012; Royston \& ReiterPalmon, 2019); CSE and creative thinking (Anderson \& Graham, 2021; Kharkhurin, 2017; Puente-Díaz \& Cavazos-Arroyo, 2017a, 2017c; Redifer et al., 2021; Tep et al., 2021); CSE and creative metacognitive indicators (Puente-Díaz \& Cavazos-Arroyo, 2020; Puente-Díaz et al., 2021); CSE and creative mindset (Royston \& ReiterPalmon, 2019). The latter group is divided into two as i) individual factors (motivational, personal, and psychological), ii) environmental factors (parent, peer influences, person-environment fit). Studies focusing on individual factors investigated the relationships between CSE and curiosity, passion, perceived encouragement, and support for autonomy (PuenteDíaz \& Cavazos-Arroyo, 2017a); CSE and achievement goals, pleasure, and curiosity (Puente-Díaz \& CavazosArroyo, 2018); CSE and development-oriented mindset (Puente-Díaz \& Cavazos-Arroyo, 2017b); CSE and intellectual risk taking (Beghetto, 2009). At the same 


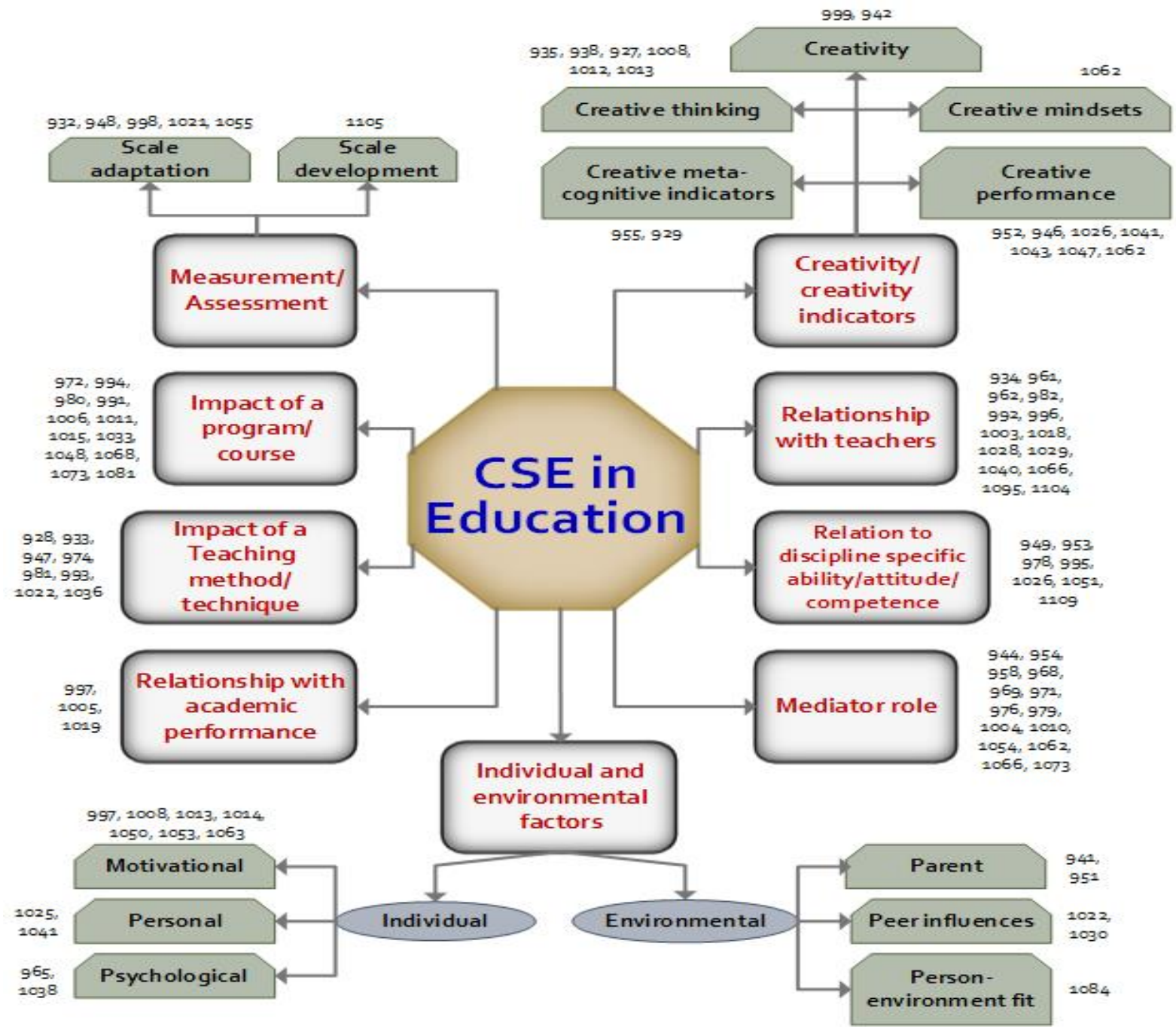

Figure 4. The nine themes and categories

Note. Each article included in the review was assigned a 4-digit numerical ID code in order to facilitate categorization process during the analysis stage.

Table 2. Frequencies of themes determined by the topics of the studies

\begin{tabular}{lc}
\hline Themes & $\mathrm{f}$ \\
\hline Relationship with creativity/creativity indicators & 18 \\
Relationship with individual and environmental factors & 16 \\
Relationship with teachers & 14 \\
Mediator role & 14 \\
The impact of a particular training program/course & 12 \\
The impact of a particular teaching method/technique & 8 \\
Relation to discipline-specific ability/attitude/competence & 7 \\
Scale development/adaptation & 6 \\
Exam score/relationship with academic performance & 3 \\
\hline
\end{tabular}

time, Al-Dhaimat et al. (2020) examined the relationship between gifted students' CSE beliefs and intellectual stress levels; Puente-Díaz and Cavazos-Arroyo (2017c) examined the role of internal and external regulation and boredom as antecedents of CSE; Beghetto (2006) investigated middle and secondary school students' motivational beliefs about CSE assessments.

De Acedo Lizarraga et al. (2014) examined the relationships between intelligence, personality, intrinsic motivation, CSE, and intellectual creativity. Taylor et al. (2020) examined how different executive functions of Attention Deficit Hyperactivity Disorder predict different components of formal divergent thinking, intellectual risk-taking, and CSE.

While examining the studies on personal characteristics, we found that Karwowski (2016) analyzed the changes occurred in 6 months (short-term) and 20 months (medium-term) periods in CSE and 
creative personal identity as well as longitudinal and cross-sequential relationships between CSE and creative personal identity. Reiter-Palmon et al. (2012) investigated the relationship between undergraduate students' self-perceptions about creativity and personality and CSE.

Review of the studies that examined the relationships between CSE and environmental factors revealed that studies investigated the effects of parents (Gralewski \& Jankowska, 2020; Liang \& Yuan, 2020), peers (Karwowski, 2015; Liu et al., 2016), and personenvironment fit (Cayirdag, 2016).

We further identified 14 studies that investigated the relationships between teachers and CSE. In these studies, the relationships between CSE and perceived teacher/school support (Chang et al., 2016; Hartley et al., 2016; Liu et al., 2021); CSE and teachers' creative role identity and encouraging creativity (Cayirdag, 2017; Huang et al., 2019); CSE and teacher expectations and evaluations (Beghetto \& Baxter, 2012; Karwowski et al. 2015); CSE and expectations from teachers (Huang et al., 2019); CSE and teacher competencies (Chang, 2018; Ovbiagbonhia et al., 2020); CSE and teachers' personal characteristics (Chand et al., 2020; Katz-Buonincontro at al., 2020a); CSE and teachers' creative behaviors (Gaziel at al., 2018; Lingke \& Chang, 2019).

Eleven of the studies examined, investigated the effect of a specific training program on CSE, and one investigated the role of CSE in the relationship between extracurricular activities and psychological adjustment (Forgeard \& Benson, 2019). In the aforementioned studies, the effects programs/courses on CSE were investigated as follows: a creativity training program (Aylesworth \& Cleary, 2020; Byrge \& Tang, 2015; Mathisen \& Bronnick, 2009; Meinel et al., 2019; Vally et al., 2019), creativity and innovation management program (Tang \& Werner, 2017), online creative thinking program (Robbins \& Kegley, 2010), long-term participatory English learning program (Liu et al., 2017), photography program (Katz-Buonincontro et al., 2020b), entrepreneurship and engineering design course (Woodcock et al., 2019), a course developed based on design thinking principles (Ohly et al., 2017).

Our examination of the studies shows that 14 of the studies investigated whether CSE mediates relationships between different variables. The variables in these studies are as follows: the relationships between multicultural experiences and creative potential (Puente-Díaz et al., 2020), family socioeconomic status and creativity (Yang et al., 2020), task motivation and creativity (Zheng et al., 2020), achievement goals and creativity (Du et al., 2020), supervisory styles and graduate student creativity (Gu et al., 2017), perceived teacher support and three forms of thinking related to creativity (Sun et al., 2021), critical thinking disposition and scientific creativity (Qiang et al., 2020), creative mindsets and creative problem-solving (Royston \& Reiter-Palmon, 2019), perceived teacher support and primary students' creative thinking (Zhang et al., 2020), proactive personality and innovative work behavior in teachers (Li et al., 2017), core self-evaluations and research performance in Chinese university teachers (Guo et al., 2019), proactive personality and innovative work behavior (Li, Liu et al., 2017), extracurricular involvement and psychological adjustment (Forgeard \& Benson, 2019). Choi (2004) investigated the psychological processes related to the effects of various individual and contextual variables on the creative performance of individuals, and whether CSE mediated this.

After examining the studies that investigate the use of a certain teaching method/technique and its effect on CSE, we saw that all of their studies included different educational technologies. Liu et al. (2014) researched the effect of story grammars on CSE of elementary students and digital storytelling. Atwood-Blaine et al. (2019) investigated CSE of children aged 9-14 in a science center using a situated mobile game. Similarly, Alt and Raichel (2020) investigated the links between gamification problem-based activities and creative self-concept (CSE and creative personal identity) of college students. Liu et al. (2016) investigated impact of peer review on CSE and learning performance in Web 2.0 learning activities. Chang et al. (2021) investigated the effects of cloudbased learning on student's engineering design creativity with different CSE. Chang et al. (2019) investigated the effect of using computer-aided design application (3D-CAD) on the CSE of high school students. Zhong et al. (2020) investigated the effects of reverse engineering pedagogy and forward-looking project-based pedagogy on the CSE of secondary school students in K-12 robotics education using quasiexperimental design. Lin and Wang (2021) used virtual reality in his EFL classroom to facilitate the CSE and intrinsic motivation of university students.

When we look at the studies examining the effect of CSE in a certain field, we notice that these studies are carried out in several fields separately (i.e. visual arts, programming, mathematics, engineering, science, music, writing), and in two studies, the effect of CSE in more than one area was investigated simultaneously. As an example of the latter, Hong et al. (2014) investigated the relationship between CSE and high school students' activities in five fields (music, visual arts, writing, science and technology); Paek et al. (2016), on the other hand, added mathematics to these fields and investigated the effect of CSE on the relationship between primary school students' ideational behavior and creative performance. Huang et al. (2020) analyzed the effects of creative thinking, psychomotor skills, and CSE on engineering design creativity. Jiajun et al. (2019) investigated the relationships between computerenabled visual creativity self-efficacy, computer self- 
efficacy, general CSE and visual creativity. Kong et al. (2018) investigated the relationship between primary school students' interest in computational thinking education, their collaborative attitudes, and their CSE. Bicer et al. (2020) examined the relationship between problem posing and mathematical CSE as a measure of mathematical creativity. In his study, Beghetto (2007) investigated whether there is a relationship between middle school and high school students' perceptions of their CSE and their perceived competencies in science.

Among the scale development/adaptation studies related to CSE, five of them are scale adaptation studies and one of them is a scale development study. In these scale adaptation studies, Atabek (2020) and KatzBuonincontro et al. (2021) used the CSE Scale developed by Tierney and Farmer (2002). Atabek (2020) developed the Turkish version of the CSE Scale developed by Tierney and Farmer (2002) and investigated its psychometric properties. Katz-Buonincontro et al. (2021) adapted the scale measuring CSE from the items developed by Beghetto (2006), and Tierney and Farmer (2002) and translated it into Mandarin. Alotaibi (2016) examined the psychometric properties of the Arabic version of the CSE inventory which is developed by Abbott (2010). Hung (2018) explored the dimensionality of the CSE Student Scale (unidimensional and multidimensional rating scale models) which is developed by Hung and Lin (2005) and revised as a 12item version (Hung, 2009; as cited in Hung, 2018) that includes the three components of the CSE with a Taiwanese sample. In this study, the 50-item Kaufman Domains of Creativity Scale (Kaufman, 2012), designed to evaluate five different areas of creativity, was adapted to a shorter 20-item scale by Tan et al. (2021).

Katz-Buonincontro et al. (2016), on the other hand, developed a scale to measure implicit beliefs about creativity in order to search out and better understand the individual student's mindset regarding their "motivation to create," and its relationship with other related constructs, for instance, CSE.

All of the studies examining the relationship between academic achievement and CSE were conducted with undergraduate and graduate students. Atwood and Pretz (2016) investigated the relationship between creativity and academic achievement in their study. The creativity measures included in this study are CSE, creative achievement, caption creativity, essay creativity, divergent thinking. Similarly, Puente-Díaz and CavazosArroyo (2018) examined the relationship between CSE and academic performance. Pretz and Kaufman (2017) researched the relationship between undergraduate students' SAT scores and their CSE.

\section{DISCUSSION}

Although the number of studies on the subject has increased in the last three years, the number of studies on CSE is still insufficient. The majority of the studies reviewed were conducted in the USA and Asian countries (e.g., China, and Taiwan). The USA, known as the country of opportunities and innovations for generations, is in great competition with Asian countries in recent years. Therefore, these countries highlight research on creativity in order to not fall behind in the competition. This is thought to be the reason why studies on CSE are conducted more often, especially in the mentioned countries. Another remarkable finding is that most of the articles (over 95\%) are single-country studies. Only four studies were conducted in the intercultural context. Thus, more studies are needed from an intercultural perspective to better understand the development of CSE and the factors affecting it, as Tang and Werner (2017) emphasized. Thus, comparative studies involving different countries could reveal how cultural differences affect the results.

About half of the studies were conducted with K-12 students and teachers, while the others were conducted with higher education students and teachers. When the studies conducted at the K12 level were examined, it was seen that the majority of these studies started from the 3rd grade. Except for the research conducted by Liang and Yuan (2020), no study investigating the CSE of 1st and 2nd-grade students could be found. In addition, we could not find any study on the CSEs of kindergarten students. In addition, while examining the literature, seven longitudinal studies were found. Five of these studies were carried out with undergraduate students and the other two with secondary school students. This is a serious limitation when considering the change and development of CSE over time (Puente-Díaz, 2016). Considering the developmental nature of CSE, such studies are needed starting from kindergarten and primary school.

When the articles that met the criteria were examined, we identified that quantitative methods were used in the vast majority of the studies. Most of these studies that used quantitative methods are based on a single questionnaire. At this point, the result obtained is limited only to the results obtained from the questionnaire used. However, more in-depth studies are needed to understand the nature, development, and effects of CSE. Considering that all methods have strengths and weaknesses, using a wider range of methods may provide us with better results (Cresswell \& Clark, 2007).

When the identified studies were categorized according to their topics, nine final themes emerged. Among these categories, there are many studies investigating the relationship of CSE with individual/environmental factors and creativity/creativity indicators, and very few studies investigating the relationship between academic performance. Likewise, when the studies are examined, it can be said that most of the studies are generally based 
on relational designs. More in-depth and longer-term studies are needed to understand how different educational curricula designed in different fields and individual and environmental factors affect CSE. As education has shifted from face-to-face to online with the effect of the COVID-19 pandemic (Chen et al., 2020; Tarkar, 2020), it affected students' CSE. There is a gap in the field about how it affects students' CSE beliefs through distance education: Therefore, there is a need for research in different disciplines (science, technology, engineering, art, etc.) on the subject. In addition, although there are studies on the effect of a certain program on creative self-efficacy among the studies examined (e.g., Liu et al., 2017; Mathisen \& Bronnick, 2009), there is no study examining the effect of STEM education on creative self-efficacy. For this reason, there is a need for research to examine the effects of educational approaches such as STEM that promise interdisciplinary teaching on CSE. Similarly, it is necessary to investigate what kind of learning environment teachers in different cultures should create in order to develop their students' CSE beliefs. There is no study investigating the effects of teachers or parents with high/low CSE on students' CSE development. Consequently, in order to develop students' CSE, working on how to provide the most suitable conditions from the first day they meet with school until they graduate from the university will contribute to the training of individuals with higher CSE.

Author contributions: All authors have sufficiently contributed to the study, and agreed with the results and conclusions.

Funding: No funding source is reported for this study.

Declaration of interest: No conflict of interest is declared by authors.

\section{REFERENCES}

Abbott, D. H. (2010). Constructing a creative self-efficacy inventory: A mixed methods inquiry (Doctoral dissertation). The University of Nebraska, Lincoln, NE.

Al-Dhaimat, Y., Albdour, N. T., \& Alshraideh, M. (2020). Creative self-efficacy and its' relationship to intellectual stress among gifted students at the Jubilee School. World Journal of Education, 10(3), 208219. https:/ / doi.org/10.5430/wje.v10n3p208

Alotaibi, K. N. (2016). Psychometric properties of creative self-efficacy inventory among distinguished students in Saudi Arabian universities. Psychological Reports, 118(3), 902-917. https:/ / doi.org/10.1177/0033294116646021

Alt, D., \& Raichel, N. (2020). Enhancing perceived digital literacy skills and creative self-concept through gamified learning environments: Insights from a longitudinal study. International Journal of Educational Research, 101, 101561. https:// doi.org/10.1016/j.ijer.2020.101561
Anderson, R. C., \& Graham, M. (2021). Creative potential in flux: The leading role of originality during early adolescent development. Thinking Skills and Creativity, 40, 100816. https://doi.org/10.1016/ j.tsc.2021.100816

Atabek, O. (2020). Adaptation of creative self-efficacy scale into Turkish language. World Journal on Educational Technology: Current Issues, 12(2), 84-97. https://doi.org/10.18844/wjet.v12i2.4639

Atwood, S. A., \& Pretz, J. E. (2016). Creativity as a factor in persistence and academic achievement of engineering undergraduates. Journal of Engineering Education, 105(4), 540-559. https:// doi.org/10.1002 /jee. 20130

Atwood-Blaine, D., Rule, A. C., \& Walker, J. (2019). Creative self-efficacy of children aged 9-14 in a science center using a situated mobile game. Thinking Skills and Creativity, 33, 100580. https://doi.org/10.1016/j.tsc.2019.100580

Aylesworth, A., \& Cleary, R. (2020). Reawakening creativity for business leaders: Removing obstacles. Journal of Education for Business, 95(4), 248-254. https:/ / doi.org/10.1080/08832323.2019.1632780

Bandura, A. (1997). Self-efficacy: The exercise of control. Freeman and Co.

Beghetto, R. A. (2006). Creative self-efficacy: Correlates in middle and secondary students. Creativity Research Journal, 18(4), 447-457. https:/ / doi.org/10.1207/s15326934crj1804_4

Beghetto, R. A. (2007). Factors associated with middle and secondary students' perceived science competence. Journal of Research in Science Teaching: The Official Journal of the National Association for Research in Science Teaching, 44(6), 800-814. https://doi.org/10.1002/tea.20166

Beghetto, R. A. (2009). Correlates of intellectual risk taking in elementary school science. Journal of Research in Science Teaching: The Official Journal of the National Association for Research in Science Teaching, 46(2), 210-223. https:/ / doi.org/10.1002/tea.20270

Beghetto, R. A., \& Baxter, J. A. (2012). Exploring student beliefs and understanding in elementary science and mathematics. Journal of Research in Science Teaching, 49(7), 942-960. https://doi.org/10.1002/ tea. 21018

Beghetto, R. A. (2013). Nurturing creativity in the micromoments of the classroom. In K. H. Kim, J. C. Kaufman, J. Baer, \& B. Sriraman (Eds.), Creatively gifted students are not like other gifted students: research, theory, and practice (pp. 3-16). Sense Publishers.

Bicer, A., Lee, Y., Perihan, C., Capraro, M. M., \& Capraro, R. M. (2020). Considering mathematical creative self-efficacy with problem posing as a measure of mathematical creativity. Educational Studies in 
Mathematics, 105(3), 457-485. https://doi.org/ 10.1007/s10649-020-09995-8

Boden, M. (2009). Creativity: How does it work?. In The idea of creativity (pp. 235-250). Brill. https:/ / doi.org/10.1163/ ej.9789004174443.i-348.74

Broekhoven, K. V., Cropley, D., \& Seegers, P. (2020). Differences in creativity across Art and STEM students: We are more alike than unalike. Thinking Skills and Creativity, 38, 100707. https:/ / doi.org/10.1016/j.tsc.2020.100707

Byrge, C., \& Tang, C. (2015). Embodied creativity training: Effects on creative self-efficacy and creative production. Thinking Skills and Creativity, 16, 51-61. https:// doi.org/10.1016/j.tsc.2015.01.002

Cayirdag, N. (2016). The relationship among creative (Mis) fit, college culture, creative and academic selfefficacy. Educational Research and Reviews, 11(15), 1382-1390. https:// doi.org/10.5897/ERR2016.2828

Cayirdag, N. (2017). Creativity fostering teaching: Impact of creative self-efficacy and teacher efficacy. Educational Sciences: Theory \& Practice, 17(6), 19591975. https:// doi.org/10.12738/estp.2017.6.0437

Chand, V. S., Kuril, S., Deshmukh, K. S., \& Avadhanam, R. M. (2020). Assessing teacher innovations: expert versus peer ratings. International Journal of Educational Management, 35(2), 467-482. https:// doi.org/10.1108/IJEM-04-2020-0185

Chang, S. H., Wang, C. L., \& Lee, J. C. (2016). Do awardwinning experiences benefit students' creative selfefficacy and creativity? The moderated mediation effects of perceived school support for creativity. Learning and Individual Differences, 51, 291-298. https:// doi.org/10.1016/j.lindif.2016.09.011

Chang, Y. C. (2018). Analyzing the moderating effect of knowledge innovation of tourism and hospitality department teachers on student creative selfefficacy and innovation behaviors by using hierarchical linear modeling. Cogent Education, 5(1), 1535755.

https:/ / doi.org/10.1080/2331186X.2018.1535755

Chang, Y. C., \& Jaisook, N. (2020). Differences in the influence of aesthetic experience on the innovative behaviors of Thai students and Chinese international students. Journal of Applied Research in Higher Education, 13(3), 900-913. https:// doi.org/10.1108/JARHE-05-2020-0133

Chang, Y. S., Chen, M. Y. C., Chuang, M. J., \& Chou, C. H. (2019). Improving creative self-efficacy and performance through computer-aided design application. Thinking Skills and Creativity, 31, 103111. https:/ / doi.org/10.1016/j.tsc.2018.11.007

Chang, Y. S., Kao, J. Y., Wang, Y. Y., \& Huang, S. C. (2021). Effects of cloud-based learning on student's engineering design creativity with different creative self-efficacy. Thinking Skills and Creativity,
40, 100813. https://doi.org/10.1016/j.tsc.2021. 100813

Chen, T., Peng, L., Jing, B., Wu, C., Yang, J., \& Cong, G. (2020). The impact of the COVID-19 pandemic on user experience with online education platforms in $\begin{array}{lll}\text { China. } & \text { Sustainability, 12(18), } 7329 .\end{array}$ https:// doi.org/10.3390/su12187329

Choi, J. N. (2004). Individual and contextual predictors of creative performance: The mediating role of psychological processes. Creativity Research Journal, 16(2-3), 187-199. https:// doi.org/10.1080/ 10400419.2004.9651452

Condron, P. (2016). An introduction to systematic reviews, with examples from health sciences and medicine. https:// unimelb.libguides.com/sysrev/inclusionexclusion-criteria

Cresswell, J. W., \& Clark, V. L. P. (2007). Designing and conducting mixed methods research. Sage Publications.

Cropley, A. J. (2011). Definitions of creativity. In M. A. Runco, \& S. R. Pritzker (Eds.), Encyclopedia of creativity (pp. 511-524). Academic Press.

De Acedo Lizarraga, M. L. S., De Acedo Baquedano, M. T. S., \& Closas, A. H. (2014). An explanatory model regarding the relationships between psychological traits and creativity. Anales de Psicología, 30(1), 355363. https:// doi.org/10.6018/analesps.30.1.153781

Du, K., Wang, Y., Ma, X., Luo, Z., Wang, L., \& Shi, B. (2020). Achievement goals and creativity: the mediating role of creative self-efficacy. Educational Psychology, 40(10), 1249-1269. https://doi.org/ 10.1080/01443410.2020.1806210

Forgeard, M. J., \& Benson, L. (2019). Extracurricular involvement and psychological adjustment in the transition from adolescence to emerging adulthood: The role of mastery and creative selfefficacy. Applied Developmental Science, 23(1), 41-58. https:/ / doi.org/10.1080/10888691.2017.1288124

Fraenkel, J. R., Wallen, N. E., \& Hyun, H. H. (2012). How to design and evaluate research in education (8th ed.). McGraw- Hill International Edition

Gaziel, H., Ifanti, A. A., \& Mendelevich, I. (2018). Antecedents of school teachers' creativity at work. Educational Practice and Theory, 40(2), 71-83. https:// doi.org/10.7459/ept/40.2.05

Gralewski, J., \& Jankowska, D. M. (2020). Do parenting styles matter? Perceived dimensions of parenting styles, creative abilities and creative self-beliefs in adolescents. Thinking Skills and Creativity, 38, 100709. https:/ / doi.org/10.1016/j.tsc.2020.100709

Gu, J., He, C., \& Liu, H. (2017). Supervisory styles and graduate student creativity: The mediating roles of creative self-efficacy and intrinsic motivation. 
Studies in Higher Education, 42(4), 721-742. https:/ / doi.org/10.1080/03075079.2015.1072149

Guo, Y., Zhu, Y., \& Zhang, L. (2019). Effect of core selfevaluations on research performance among Chinese university teachers. Current Psychology, 38(5), 1253-1257. https://doi.org/10.1007/s12144017-9685-6

Haase, J., Hoff, E. V., Hanel, P. H., \& Innes-Ker, Å. (2018). A meta-analysis of the relation between creative self-efficacy and different creativity measurements. Creativity Research Journal, 30(1), 1-16. https: / / doi.org/10.1080/10400419.2018.1411436

Hanif, S., Wijaya, A. F. C., \& Winarno, N. (2019). Enhancing students' creativity through STEM project-based learning. Journal of Science Learning, 2(2), 50-57.

Hartley, K. A., Plucker, J. A., \& Long, H. (2016). Creative self-efficacy and teacher ratings of student creativity in Chinese elementary classrooms. Thinking Skills and Creativity, 22, 142-151. https://doi.org/10.1016/j.tsc.2016.10.001

Hong, E., Hartzell, S. A., \& Greene, M. T. (2009). Fostering creativity in the classroom: Effects of teachers' epistemological beliefs, motivation, and goal orientation. The Journal of Creative Behavior, 43(3), 192-208. https://doi.org/10.1002/j.21626057.2009.tb01314.x

Hong, E., Peng, Y., \& O’Neil Jr, H. F. (2014). Activities and accomplishments in various domains: Relationships with creative personality and creative motivation in adolescence. Roeper Review, 36(2), 92-103. https://doi.org/10.1080/02783193. 2014.884199

Hong, J. C., Ye, J. H., \& Fan, J. Y. (2019). STEM in fashion design: The roles of creative self-efficacy and epistemic curiosity in creative performance. EURASIA Journal of Mathematics, Science and Technology Education, 15(9), em1742. https:/ / doi.org/10.29333/ejmste/108455

Huang, N. T., Chang, Y. S., \& Chou, C. H. (2020). Effects of creative thinking, psychomotor skills, and creative self-efficacy on engineering design creativity. Thinking Skills and Creativity, 37, 100695. https://doi.org/10.1016/j.tsc.2020.100695

Huang, X., Lee, J. C. K., \& Dong, X. (2019). Mapping the factors influencing creative teaching in mainland China: An exploratory study. Thinking Skills and Creativity, 31, 79-90. https://doi.org/10.1016/ j.tsc.2018.11.002

Huang, X., Lee, J. C. K., \& Yang, X. (2019). What really counts? Investigating the effects of creative role identity and self-efficacy on teachers' attitudes towards the implementation of teaching for creativity. Teaching and Teacher Education, 84, 57-65. https://doi.org/10.1016/j.tate.2019.04.017
Hung, S. P., \& Lin, S. S. J. (2005). Self-efficacy about creativity: the development of questionnaire with confirmatory factor analysis [Poster presentation]. 113th annual convention of American psychological association.

Hung, S. P. (2018). Validating the creative self-efficacy student scale with a Taiwanese sample: An item response theory-based investigation. Thinking Skills and Creativity, 27, 190-203. https:// doi.org/10.1016 /j.tsc.2018.02.006

Jiajun, G., Islam, A. A., Teo, T., \& Spector, J. M. (2019). Computer-enabled visual creativity: An empirically based model with implications for learning and instruction. Instructional Science, 47(5), 609-625. https:/ / doi.org/10.1007/s11251-019-09487-0

Jaiswal, N. K., \& Dhar, R. L. (2015). Transformational leadership, innovation climate, creative selfefficacy and employee creativity: A multilevel study. International Journal of Hospitality Management, 51, 30-41. https://doi.org/10.1016/ j.ijhm.2015.07.002

Karwowski, M. (2015). Peer effect on students' creative self-concept. The Journal of Creative Behavior, 49(3), 211-225. https:/ / doi.org/10.1002/jocb.102

Karwowski, M. (2016). The dynamics of creative selfconcept: Changes and reciprocal relations between creative self-efficacy and creative personal identity. Creativity Research Journal, 28(1), 99-104. https:/ / doi.org/10.1080/10400419.2016.1125254

Karwowski, M., \& Barbot, B. (2016). Creative self-beliefs: Their nature, development, and correlates. In J. C. Kaufman \& J. Baer (Eds.). Creativity and reason in cognitive development (pp. 302-326). Cambridge University Press. https://doi.org/10.1017/ CBO9781139941969.016

Karwowski, M., Gralewski, J., \& Szumski, G. (2015). Teachers' effect on students' creative self-beliefs is moderated by students' gender. Learning and Individual Differences, 44, 1-8. https://doi.org/ 10.1016/j.lindif.2015.10.001

Karwowski, M., \& Lebuda, I. (2016). The big five, the huge two, and creative self-beliefs: A metaanalysis. Psychology of Aesthetics, Creativity, and the Arts, 10(2), 214-232. https://doi.org/10.1037/ aca0000035

Katz-Buonincontro, J., Hass, R., \& Perignat, E. (2020a). Measuring beliefs about teaching for creativity. Teachers College Record, 122(7), 1-22.

Katz-Buonincontro, J., Hass, R., \& Perignat, E. (2020b). Triangulating creativity: Examining discrepancies across self-rated, quasi-expert-rated and verbalized creativity in arts-based learning. The Journal of Creative Behavior, 54(4), 948-963. https://doi.org/ 10.1002/jocb.424 
Katz-Buonincontro, J., Hass, R., Kettler, T., Tang, L. M., \& Hu, W. (2021). Partial measurement invariance of beliefs about teaching for creativity across US and Chinese educators. British Journal of Educational Psychology, 91(2), 563-583. https://doi.org/10.1111 /bjep.12379

Katz-Buonincontro, J., Hass, R., \& Reiter-Palmon, R. (2016). To create or not to create? That is the question: Students' beliefs about creativity. AERA Online Paper Repository.

Kaufman, J. C. (2012). Counting the muses: development of the Kaufman domains of creativity scale (KDOCS). Psychology of Aesthetics, Creativity, and the Arts, 6(4), 298-308. https://doi.org/10.1037/ a0029751

Kong, S. C., Chiu, M. M., \& Lai, M. (2018). A study of primary school students' interest, collaboration attitude, and programming empowerment in computational thinking education. Computers $\mathcal{E}$ Education, 127, 178-189. https://doi.org/10.1016/ j.compedu.2018.08.026

Kharkhurin, A. V. (2017). Does the eye of the beholder construct beauty? Contributions of self-efficacy factors to divergent thinking traits. Creativity Research Journal, 29(4), 370-376. https:/ / doi.org/10.1080/10400419.2017.1376493

Lemons, G. (2010). Bar drinks, rugas, and gay pride parades: Is creative behavior a function of creative self-efficacy?. Creativity Research Journal, 22(2), 151161.

https:/ / doi.org/10.1080/10400419.2010.481502

Li, C. H., \& Wu, J. J. (2011). The structural relationships between optimism and innovative behavior: Understanding potential antecedents and mediating effects. Creativity Research Journal, 23(2), 119-128.

https:/ / doi.org/10.1080/10400419.2011.571184

Li, M., Liu, Y., Liu, L., \& Wang, Z. (2017). Proactive personality and innovative work behavior: The mediating effects of affective states and creative self-efficacy in teachers. Current Psychology, 36(4), 697-706. https://doi.org/10.1007/s12144-0169457-8

Liang, C. C., \& Yuan, Y. H. (2020). Exploring children's creative self-efficacy affected by after-school program and parent-child relationships. Frontiers in Psychology, 11, 2237. https://doi.org/10.3389/ fpsyg.2020.02237

Lin, Y. J., \& Wang, H. C. (2021). Using virtual reality to facilitate learners' creative self-efficacy and intrinsic motivation in an EFL classroom. Education and Information Technologies, 26, 4487-4505. https:/ / doi.org/10.1007/s10639-021-10472-9

Lingke, K. O. N. G., \& Chang, Y. C. (2019). The effect of teachers' savoring on creative behaviors: Mediating effects of creative self-efficacy and aesthetic experience. International Journal of Educational Methodology, 5(3), 325-335. https://doi.org/ 10.12973/ijem.5.3.325

Liu, C. C., Chen, W. C., Lin, H. M., \& Huang, Y. Y. (2017). A remix-oriented approach to promoting student engagement in a long-term participatory learning program. Computers \& Education, 110, 1-15. https://doi.org/10.1016/j.compedu.2017.03.002

Liu, C. C., Lu, K. H., Wu, L. Y., \& Tsai, C. C. (2016). The impact of peer review on creative self-efficacy and learning performance in Web 2.0 learning activities. Journal of Educational Technology E Society, 19(2), 286-297.

Liu, C. C., Wu, L. Y., Chen, Z. M., Tsai, C. C., \& Lin, H. M. (2014). The effect of story grammars on creative self-efficacy and digital storytelling. Journal of Computer Assisted Learning, 30(5), 450-464. https://doi.org/10.1111/jcal.12059

Liu, X. X., Gong, S. Y., Zhang, H. P., Yu, Q. L., \& Zhou, Z. J. (2021). Perceived teacher support and creative self-efficacy: The mediating roles of autonomous motivation and achievement emotions in Chinese junior high school students. Thinking Skills and Creativity, 39, 100752. https://doi.org/10.1016/ j.tsc.2020.100752

Locke, E. A. (1997). Self-efficacy: The exercise of control. Personnel Psychology, 50(3), 801-804.

Mathisen, G. E., \& Bronnick, K. S. (2009). Creative selfefficacy: An intervention study. International Journal of Educational Research, 48(1), 21-29. https:// doi.org/10.1016/j.ijer.2009.02.009

Meinel, M., Wagner, T. F., Baccarella, C. V., \& Voigt, K. I. (2019). Exploring the effects of creativity training on creative performance and creative self-efficacy: Evidence from a longitudinal study. The Journal of Creative Behavior, 53(4), 546-558. https://doi.org/ 10.1002/jocb.234

Miles, M. B., \& Huberman, A. M. (1994). Qualitative data analysis: An expanded sourcebook. Sage.

Ohly, S., Plückthun, L., \& Kissel, D. (2017). Developing students' creative self-efficacy based on designthinking: Evaluation of an elective university course. Psychology Learning \& Teaching, 16(1), 125132. https:/ / doi.org/10.1177/1475725716681714

Ovbiagbonhia, A. R., Kollöffel, B., \& Den Brok, P. (2020). Teaching for innovation competence in higher education Built Environment engineering classrooms: Teachers' beliefs and perceptions of the learning environment. European Journal of Engineering Education, 45(6), 917-936. https:/ / doi.org/10.1080/03043797.2020.1784097

Oxman, A. D. (1994). Systematic reviews: Checklists for review articles. British Medical Journal, 309(6955), 
648-651.

https:/ / doi.org/10.1136/bmj.309.6955.648

Paek, S. H., Park, H., Runco, M. A., \& Choe, H. S. (2016). The contribution of ideational behavior to creative extracurricular activities. Creativity Research Journal, 28(2), 144-148. https://doi.org/10.1080/10400419. 2016.1162547

Park, N. K., Jang, W., Thomas, E. L., \& Smith, J. (2021). How to organize creative and innovative teams: creative self-efficacy and innovative team performance. Creativity Research Journal, 33(2), 168179.

https:/ / doi.org/10.1080/10400419.2020.1842010

Petticrew, M., \& Roberts, H. (2006). Systematic reviews in the social sciences: A practical guide. Blackwell Publishing.

Pretz, J. E., \& Kaufman, J. C. (2017). Do traditional admissions criteria reflect applicant creativity?. The Journal of Creative Behavior, 51(3), 240-251. https:/ / doi.org/10.1002/jocb.120

Puente-Díaz, R. (2016). Creative self-efficacy: An exploration of its antecedents, consequences, and applied implications. The Journal of Psychology, 150(2), 175-195. https:/ / doi.org/10.1080/00223980. 2015.1051498

Puente-Díaz, R., \& Cavazos-Arroyo, J. (2017a). Creative self-efficacy: The influence of affective states and social persuasion as antecedents and imagination and divergent thinking as consequences. Creativity Research Journal, 29(3), 304-312. https: / / doi.org/10.1080/10400419.2017.1360067

Puente-Díaz, R., \& Cavazos-Arroyo, J. (2017b). The influence of creative mindsets on achievement goals, enjoyment, creative self-efficacy and performance among business students. Thinking Skills and Creativity, 24, 1-11. https:/ / doi.org/10.1016/j.tsc.2017.02.007

Puente-Díaz, R., \& Cavazos-Arroyo, J. (2017c). Creative self-efficacy: The role of self-regulation for schoolwork and boredom as antecedents, and divergent thinking as a consequence. Social Psychology of Education, 20(2), 347-359. https:/ / doi.org/10.1007/s11218-017-9376-Z

Puente-Díaz, R., \& Cavazos-Arroyo, J. (2018). An exploration of some antecedents and consequences of creative self-efficacy among college students. The Journal of Creative Behavior, 52(3), 256-266. https:/ / doi.org/10.1002/jocb.149

Puente-Díaz, R., \& Cavazos-Arroyo, J. (2020). Creative metacognitive feelings as a source of information for creative self-efficacy, creativity potential, intrapersonal idea selection, and task enjoyment. The Journal of Creative Behavior, 54(3), 499-507. https:/ / doi.org/10.1002/jocb.384
Puente-Díaz, R., Cavazos-Arroyo, J., \& Puerta-Sierra, L. (2021). Idea generation, selection, and evaluation: A metacognitive approach. The Journal of Creative Behavior. https:/ / doi.org/10.1002/jocb.505

Puente-Díaz, R., Toptas, S. D., Cavazos-Arroyo, J., Wimschneider, C., \& Brem, A. (2020). Creative potential and multicultural experiences: The mediating role of creative self-efficacy. The Journal of Creative Behavior, 54(4), 815-823. https://doi.org/10.1002/jocb.408

Qiang, R., Han, Q., Guo, Y., Bai, J., \& Karwowski, M. (2020). Critical thinking disposition and scientific creativity: The mediating role of creative selfefficacy. The Journal of Creative Behavior, 54(1), 90-99. https:// doi.org/10.1002/jocb.347

Redifer, J. L., Bae, C. L., \& Zhao, Q. (2021). Self-efficacy and performance feedback: Impacts on cognitive load during creative thinking. Learning and Instruction, 71, 101395. https://doi.org/10.1016/ j.learninstruc.2020.101395

Reiter-Palmon, R., Robinson-Morral, E. J., Kaufman, J. C., \& Santo, J. B. (2012). Evaluation of selfperceptions of creativity: Is it a useful criterion?. Creativity Research Journal, 24(2-3), 107-114. https:/ / doi.org/10.1080/10400419.2012.676980

Robbins, T. L., \& Kegley, K. (2010). Playing with Thinkertoys to build creative abilities through online instruction. Thinking Skills and Creativity, 5(1), 40-48. https://doi.org/10.1016/j.tsc.2009.07. 001

Royston, R., \& Reiter-Palmon, R. (2019). Creative selfefficacy as mediator between creative mindsets and creative problem-solving. The Journal of Creative Behavior, 53(4), 472-481. https://doi.org/10.1002/ jocb. 226

Schott, C., Van Roekel, H., \& Tummers, L. (2020). Teacher leadership: A systematic review, methodological quality assessment and conceptual framework. Educational Research Review, 100352. https:/ / doi.org/10.1016/j.edurev.2020.100352

Shin, S. J., Kim, T. Y., Lee, J. Y., \& Bian, L. (2012). Cognitive team diversity and individual team member creativity: A cross-level interaction. Academy of Management Journal, 55(1), 197-212. https:/ / doi.org/10.5465/amj.2010.0270

Sun, C., Zhou, Z., Yu, Q., Gong, S., Yi, L., \& Cao, Y. (2021). Exploring the effect of perceived teacher support on multiple creativity tasks: Based on the expectancy-value model of achievement motivation. The Journal of Creative Behavior, 55(1), 15-24. https:/ / doi.org/10.1002/jocb.430

Tan, C. S., Tan, S. A., Cheng, S. M., Hashim, I. H. M., \& Ong, A. W. H. (2021). Development and preliminary validation of the 20-item Kaufman domains of Creativity Scale for use with Malaysian 
populations. Current Psychology, 40(4), 1946-1957. https:/ / doi.org/10.1007/s12144-019-0124-8

Tang, M., \& Werner, C. H. (2017). An interdisciplinary and intercultural approach to creativity and innovation: Evaluation of the EMCI ERASMUS intensive program. Thinking Skills and Creativity, 24, 268-278. https:/ / doi.org/10.1016/j.tsc.2017.04.001

Tang, M., Hu, W., \& Zhang, H. (2017). Creative selfefficacy from the Chinese perspective: Review of studies in mainland China, Hong Kong, Taiwan, and Singapore. In M. Karwowski, \& J. C. Kaufman (Eds.), The creative self (pp. 237-257). Academic Press. https:/ / doi.org/10.1016/B978-0-12-8097908.00013-3

Tarkar, P. (2020). Impact of COVID-19 pandemic on education system. International Journal of Advanced Science and Technology, 29(9), 3812-3814.

Taylor, C. L., Zaghi, A. E., Kaufman, J. C., Reis, S. M., \& Renzulli, J. S. (2020). Characteristics of ADHD related to executive function: Differential predictions for creativity-related traits. The Journal of Creative Behavior, 54(2), 350-362. https:// doi.org/10.1002/jocb.370

Tep, P., Maneewan, S., Chuathong, S., \& Easter, M. A. (2021). The relationship between human values and creative ideation among undergraduate students: The role of creative self-efficacy. Cogent Psychology, 8(1), 1885575. https://doi.org/10.1080/23311908. 2021.1885575

Tierney, P., \& Farmer, S. M. (2002). Creative self-efficacy: Its potential antecedents and relationship to creative performance. Academy of Management Journal, 45(6), 1137-1148. https://doi.org/10.5465/ 3069429

Tierney, P., \& Farmer, S. M. (2011). Creative self-efficacy development and creative performance over time.
Journal of Applied Psychology, 96(2), 277. https:// doi.org/10.1037/a0020952

Vally, Z., Salloum, L., AlQedra, D., El Shazly, S., Albloshi, M., Alsheraifi, S., \& Alkaabi, A. (2019). Examining the effects of creativity training on creative production, creative self-efficacy, and neuro-executive functioning. Thinking Skills and Creativity, 31, 70-78. https://doi.org/10.1016/ j.tsc.2018.11.003

Woodcock, C. S., Shekhar, P., \& Saad, A. H. (2019). Examining project-based entrepreneurship and engineering design course professional skills outcomes. The International Journal of Engineering Education, 35(2), 631-644.

Yang, Y., Xu, X., Liu, W., \& Pang, W. (2020). Hope and creative self-efficacy as sequential mediators in the relationship between family socioeconomic status and creativity. Frontiers in Psychology, 11, 438. https:// doi.org/10.3389/fpsyg.2020.00438

Zhang, H., Sun, C., Liu, X., Gong, S., Yu, Q., \& Zhou, Z. (2020). Boys benefit more from teacher support: Effects of perceived teacher support on primary students' creative thinking. Thinking Skills and Creativity, 37, 100680. https://doi.org/10.1016/ j.tsc. 2020.100680

Zheng, J., Wu, G., \& Li, H. (2020). Motivating civil engineering students' creativity: Actor-partner interdependence approach. Journal of Civil Engineering Education, 146(1), 04019002.

Zhong, B., Kang, S., \& Zhan, Z. (2020). Investigating the effect of reverse engineering pedagogy in K-12 robotics education. Computer Applications in Engineering Education, 29(5), 1097-1111. https://doi.org/10.1002/cae.22363

\section{http://www.ejmste.com}

